\title{
The challenge of healthcare for consensus public reason
}

\begin{abstract}
This paper argues that religious and other 'non-public' reasoning can have a legitimate and beneficial role in justifying health-related resource allocation decisions affecting individuals, subpopulations and whole communities. Section I critically examines Norman Daniels' exclusion of such reasoning from such justifications. Section II shows the inadequacy of Daniels' approach to healthcare as a matter of basic justice, arguing that consensus public reason is indeterminate in certain areas of healthcare policy, including the use of life-sustaining resources and issues related to risk and responsibility. Section III shows how resource allocation decision-making can appropriately incorporate religious and 'non-public' reasoning via the medical professional practice of collaborative deliberation.
\end{abstract}

Keywords (6)

public reason, indeterminacy, healthcare, medical professionalism, religious reasoning, Norman Daniels. 


\section{Introduction}

This paper argues that religious and other 'non-public' reasoning can have a legitimate and beneficial role in justifying health-related resource allocation decisions affecting individuals, subpopulations and whole communities. If this is so, consensus notions of public reason which exclude such reasoning from such justifications are mistaken. I focus on consensus public reason because it is the dominant view of public reason and because the leading exponent of public reason in healthcare, Norman Daniels, takes this approach. I will not engage in any detail with convergence public reason primarily because its advocates have not applied it in the granularities of healthcare. I think they could do so and perhaps make use of some of my approach. However, reasons of space prevent me from developing that possibility.

Daniels and Rawls think that public reason must apply to constitutional essentials and matters of basic justice, including healthcare. Such consensus public reason requires a 'restriction of the reasons that may be invoked in justifying exercises of political power to those that can be recognised as in some sense good or acceptable grounds for political action by all qualified members of the community.' (Williams 2017: 2) Public reason's 'foundational commitment is to the moral claim that persons (or citizens) are free and equal, and thus the exercise of political power is legitimate only when it can be publicly justified' (Quong 2011: 2-3). That public justification 'has to depend on reasons that every citizen could in principle find admissible, or recognise as having normative force.' (Billingham and Chaplin 2019: 130) This means that 'reasons drawn from reasonable citizens' religions, metaphysics, conceptions of the good, and other aspects of their 'comprehensive doctrines' cannot count as justificatory.' (Williams 2017: 2) Instead, public reason liberalism 'imposes upon all individuals who share in the exercise of the state's coercive power, including ordinary voters, a moral 'duty of civility' to advocate and lend support to only [sic] political initiatives that are publicly justified according to the foregoing standards.' (Williams 2017: 2)

Healthcare presents a challenge to consensus public reason because it routinely deals in existential questions of human life. These concern individuals', sub-populations' and political communities' most basic needs and enduringly contentious views. Healthcare poses such questions in concentrated, concrete form, challenging consensus public reason's competence to deal decisively with public affairs without recourse to 'non-public' reasoning. My argument aims to show that consensus public reason is incomplete - in the sense of indeterminate - concerning some important elements of healthcare. This indeterminacy opens up a justificatory role for religious and other 'non-public' reasons in decision-making, lessening the appeal of public reason as a whole.

The paper argues that, in contrast with consensus public reason, doctors' traditions of practice are well-accustomed to incorporating religious and other 'non-public' reasoning in deliberating about and justifying decisions. Medical professionals' practice of 'collaborative deliberation' allows for religious reasoning and practices to justify decisions on allocating public resources (for example, whether to continue life-extending treatment for those suffering brain-stem death). In such cases, resources are used for religious reasons. This is not of merely personal significance. The allocation determines what resources remain available to others of no religion and other religions. Furthermore, the role of religious reasoning in individual decision-making may be legitimately and beneficially replicated throughout various levels of health-related resource allocation deliberation, decision-making and policy. What may be appropriate to deliberation and decision-making for individual patients may be similarly appropriate for cohorts and communities. The same would apply for comprehensive accounts of the good which do not draw on religious sources. 
In section I, I consider Daniels' application of consensus public reason to healthcare which rejects any role for religious or comprehensive reasoning in justifying resource allocation decisions. In section II, I critique Daniels, arguing that consensus public reason is indeterminate concerning policies across several areas of healthcare policy and practice, including the determination of death, use of life-sustaining resources, gender transition medicine, abortion, IVF and issues related to risk and responsibility, focussing on the risk of genetic disorders among children conceived in consanguineous unions. In section III, I offer an alternative way of framing deliberation and decision-making in resource allocation via the medical professional practice of collaborative deliberation.

\section{Public reason, justice and healthcare}

Rawls called the application of his theory of justice to healthcare a 'problem of extension' (Rawls 2005: 20-21). He did not pursue it ${ }^{1}$ but endorsed Daniels on the matter (Rawls 2005: $21 \mathrm{fn} 24$, 184fn14). ${ }^{2}$ Daniels argues that health is a matter of basic justice:

Failing to promote health in a population...failing to promote normal functioning...fails to protect the opportunity or capability of people to function as free and equal citizens... when we could reasonably do otherwise... [this] is a failure to provide us with what we owe each other. It is unjust. (Daniels 2008: 14)

Daniels thinks health is essential to citizens' fair equality of opportunity to pursue their life-plans: 'health is of special moral importance because it contributes to the range of exercisable or effective opportunities open to us.' (Daniels 1985: 2) He comments that 'we can explain the importance we attribute to meeting health-care needs once we observe the effect of disease on an individual's share of the normal opportunity range.' (Daniels 1985: 39; cf. 47 and Daniels 2008: 81) Though health 'is not happiness and confusing the two over-medicalizes social philosophy' (Daniels 1985: 29), 'a person [is] happy when he is successful in carrying out his plan'. This makes 'the kinds of needs picked out by reference to normal species functioning... objectively important because they meet this fundamental interest persons have in maintaining a normal range of opportunities.' (Daniels 1985: 28) Health is therefore a matter of basic justice if, as Rawls held (and Daniels agrees), justice concerns fair equality of opportunity. ${ }^{3}$

This conclusion counts against situating healthcare outside the scope of public reason. This could be the case if the scope were limited to 'constitutional essentials'. However, Rawls thought that the scope of public reason concerned matters of basic justice as well as constitutional essentials (Rawls 2005: 225). Another way to exclude healthcare from public reason would be not to count it a matter of basic justice. However, Daniels' argument convincingly rebuts this view. Moreover, Rawls himself lists basic healthcare for all as something required as a matter of basic justice (Rawls 2005: lvii). It is an issue which he explicitly hopes his political conception can address - suggesting it falls within the scope of public reason (Rawls 2005: 21). This indicates that the designation of how to govern a certain societal activity as 'a problem of extension' does not entail that it is not a

\footnotetext{
${ }^{1}$ Daniels suggests that 'because health care needs behave in [an] especially unruly way, Rawls deliberately leaves consideration of them out of the theory.' (Daniels, N. 'Rights to health care and distributive justice: Programmatic worries' Journal of Medicine and Philosophy 4 (2):174-191 (1979), p.181) Rid argues that 'Health and healthcare are not a topic for Rawls, as he assumes all members of society to be healthy.' (Rid A. 'Justice and procedure: how does “accountability for reasonableness" result in fair limit-setting decisions?' Journal of Medical Ethics 2009;35:12-16, p.12)

2 Daniels' works which Rawls endorsed appeared before Daniels devised 'accountability for reasonableness' (see below) or considered the social determinants of health. Nonetheless, Rawls' recommendation gives good grounds to recognise Daniels' status as an authoritative mediator of Rawlsian tradition for health and healthcare.

3 Justice is clearly not reducible to securing fair equality of opportunity. Rather, Daniels is 'broadening Rawls's principle so that it protects[s] individual shares of the normal opportunity range and not merely access to jobs and offices.' (Daniels 2005: 57)
} 
matter of basic justice. Whether public reason can be effectively applied to extension problems therefore matters for the completeness of public reason. ${ }^{4}$

\section{Accountability for Reasonableness (AFR)}

Since healthcare is a matter of basic justice to which public reason must apply, the challenge of how to do so follows. Daniels proposes a specific public reason procedure to dispense justice in healthcare. It concerns what justifications are permitted for resource allocation decisions which affect citizens' interests in maintaining a normal opportunity range. These decisions routinely have coercive force, preventing some from accessing what they desire, indicating that the justificatory procedure covering such decisions should be governed by public reason. He observes that the

moral controversy that surrounds the creation of winners and losers in resource allocation decisions results in a legitimacy problem: Under what conditions do decision makers have the moral authority to set the limits they impose? (Daniels 2008: 103)

[Since] questions about the fairness and legitimacy of limit setting are appropriately posed from the perspective of those whose health needs are not met because others' needs are met instead, we should ask: Why or when - under what conditions - should patients or clinicians... who think an uncovered service (or unprotected risk) is appropriate or even medically necessary accept as legitimate the limit-setting decision of a health plan or district authority...? (Daniels 2008: 108; italicisation added)

There is an existential abruptness to the problem: on what grounds may an authority benefit some citizens by denying to others what seems 'appropriate or even medically necessary', directly affecting their continued existence, life's course and life's ending? This shows why limiting public reason's scope to the justification of laws is inadequate. The justification of specific policy decisions to allocate certain healthcare resources will be just as if not more important to citizens, whether as cohorts affected by a common disease or as individuals. Note that, for Daniels, justification by public reason applies at the level of insurance cover or local healthcare authority. This is in addition to the legislative level, at which the lawfulness of any specific policy is judged.

Daniels' recommended public reason procedure, 'Accountability for Reasonableness' (AFR), constrains what reasoning is legitimate for justifying allocation decisions. The AFR procedure requires that deliberation takes place in such a way that 'fair-minded' people may be satisfied even if denied the decision they wanted. ${ }^{5}$ What is 'fair' about the procedure is articulated through its four conditions, namely (1) Publicity (2) Relevance (3) Revision and Appeals (4) Enforcement (Daniels 2008: 118-119). These four are succinctly summarised elsewhere (Friedman 2008: 101102). ${ }^{6}$ (1) and (4) are important but not to the point here. ${ }^{7}$ The most decisive for public reason is (2), the 'relevance condition', which bears directly on the determination of justice. Decisions may only be just if the reasons given are 'relevant'. Condition (3) is governed by (2) in that the legitimacy of evidence or arguments used to appeal against a decision is determined by their 'relevance'.

\footnotetext{
${ }^{4}$ Quong (2011: 256-289) argues that public reason should apply to all political decisions and deliberations, in which case it certainly applies to healthcare. Even if one rejects Quong, Daniels' more circumscribed view, that healthcare is a matter of basic justice and subject to public reason requirements, remains and is endorsed by Rawls. This latter view is sufficient for the argument here.

${ }^{5}$ By 'fair-minded' Daniels insists he does 'not simply mean my friends or people who happen to agree with me [but] people who seek to cooperate with others on terms they can justify to each other.' (Daniels 2008: 117)

6 See Friedman 2008:101-102.

7 Publicity Condition: Decisions regarding both direct and indirect limits to care and their rationales must be publicly accessible...Enforcement Condition: There is either voluntary or public regulation of the process to ensure that conditions 1-3 are met.' (Friedman 2008: 101-102)
} 
As regards 'relevance', the

...deliberative view of democratic legitimacy imposes some constraints on the kinds of reasons that can play a role in deliberation. Reasons must reflect the fact that all parties to a decision are viewed as seeking terms of fair cooperation that all can accept as reasonable. Where their well-being or fundamental liberties or other matters of fundamental value are involved and at risk, people should not be expected to accept binding terms of cooperation that rest on types of reasons they find unacceptable. For example, reasons that rest on matters of religious faith will not meet this condition. Reasonable people differ in their religious, philosophical, and moral views, and yet we must seek terms of fair cooperation that rest on justifications acceptable to all. (Daniels 2008: 112-113) ${ }^{8}$

Reasons presented in deliberation and in binding terms of cooperation must not be merely intelligible to others but rather should be 'acceptable to all'. It is, paradigmatically, 'reasons that rest on matters of religious faith' that are excluded. The constraint is broad. It bans religious reasoning wherever people's 'well-being' is at risk. For Daniels, rejecting religious reasons is essential to demarcating what counts as reasonable:

publicly accessible criteria... [are contrasted] with ones that derive from specific religious views not accessible to nonbelievers, such as the belief that an unproven remedy ought to be available because it might be the occasion for a miracle. (Daniels 2008: 125)

Medical professionalism and accountability for reasonableness

This rejection of non-public, especially religious reasoning from deliberation and justification is important for AFR's application to medical professional practice. Daniels regrets that physicians commonly 'resist the role of gatekeeper or steward of medical resources, even if this promotes fair distribution' (Daniels 2008: 219). He advocates strict constraints on professionals to ensure such distribution. Doctors' decisions should be 'uninfluenced by judgments about patients' worth' (Daniels 2008: 234). He thinks that

physicians should not decide how much it is worth to save or extend a particular patient's life. More narrowly interpreted [this] constraint...bars physicians from considering facts other than medical need or likelihood of treatment success in making clinical decisions for a particular patient. (Daniels 2008: 234)

Daniels' recommendation, couched in the paternalist language of making decisions for patients, is to eliminate physicians' attention to patients' particular values and beliefs in clinical decisions. This seems at odds with his commitment to 'autonomy' (Daniels 2008: 234) ${ }^{9}$ but is governed instead by the claim that:

institutions - and physicians working with them - must be accountable for the reasonableness of their limit-setting behavior... They must publicly show that the decisions about these limits rest on reasons that all consider relevant to meeting the health needs of a population under reasonable resource constraints. (Daniels 2008: 238)

\footnotetext{
8 This is distinguished from a majoritarian view (Daniels 2008: 113).

9 'Clinical decisions must be (A) competent, complying with professional standards of care; (B) respectful of patient autonomy; (C) respectful of patient rights, such as confidentiality; (D) free from consideration of physicians' interests; (E) uninfluenced by judgments about patients' worth.' (Daniels 2008: 234)
} 
AFR would govern institutions and physicians by preventing them from allowing any justificatory role to 'non-public' reasons (e.g. patients' religious views) in decisions about allocating resources. Instead, Daniels claims that doctors as 'Ideal Advocates may not do things that would be unfair or unjust to other patients. This is the sense in which justice is primary or provides the framework for professional ethics.' (Daniels 2008: 236) Thus they may not in any way justify resource usage based on non-public and especially religious reasoning since such a decision could not be accepted as reasonable by all. 'Physicians can still advocate effectively for their patients' but 'within the limits imposed by justice'. (Daniels 2008: 237) Thus religious reasoning may not justify resource allocation decisions concerning individuals, policies affecting populations or relevant legislation. At all levels, any religious justification would unjustly constrain the resources available to all because decisions thus justified would be based on reasons not acceptable to all.

Daniels' position, though severe in excluding patients' religious beliefs, is coherent. He opposes religious reasoning in justifications for allocation decisions because of the need for coherence between the justifications permitted for individual treatments and for population-level policies. Unlike many other areas of public spending, citizens deploying 'non-public' reasons in healthcare would have vast scope to impose their will to use resources to others' detriment.

However, by repeatedly illustrating religion's influence in terms of patients' expectations of miracles imposing unwarranted costs on others for treatments which are not clinically indicated, ${ }^{10}$ Daniels displays a rather narrow view of how religious beliefs inform people's understanding of health. While there are instances of the sort he criticises, he overlooks more important kinds of case. Consider what health provision there should be for individuals and communities who act on the belief that the risks of genetic disease in children conceived through consanguineous marriages are worth bearing for the sake of the benefits such marriages confer. Or take the case of those who, for religious reasons, continue with a pregnancy in which the child in utero will die soon after birth and the continuance of which may pose serious risks to the health of the mother. In each case, there are costs to the public which seem unjustifiable in public reason terms because they require that others live with the consequences of non-public reasoning.

Daniels avoids such detailed engagement. He believes that religion is especially harmful to health, exacerbating health problems and correlated to many 'risky behaviors' (Daniels 2008: 157). Persistent inequalities 'are significantly affected by bias associated with cultural and religious practices' (Daniels 2008: 22). Similarly, 'gender-biased attitudes, with their deep cultural and religious roots' are decried (Daniels 2008: 52). These criticisms have truthful applications (Mkhonto and Hanssen 2018) but ignore any more complex relationship religion might have with health, or any positive contribution religion might make. ${ }^{11}$

In summary, Daniels answers Rawls' challenge to make public reason liberalism concrete. Since 'philosophical investigation into the implications of public reasoning for concrete political questions remains surprisingly rare' (Williams 2017: 1), Daniels' contribution is particularly important. He rejects any role for religious reasoning in healthcare resource allocation, arguing that public reason requires the complete exclusion of such reasoning from justification for such decisions at all levels. His view seems motivated by a desire to prevent harm and unconstrained cost, considering the burdens which might be imposed on societies if religious reasoning is allowed a public justificatory role.

\footnotetext{
10 Note Daniels and Sabin (2002: 53) where exactly the same example is used, indicating a long-term disinterest in religious people's ways of conceiving their health.

11 The one tortuous concession to religion's possible benefits I have unearthed is that 'religious...differences in lifestyle...might give rise...to health inequalities that we would not consider unjust.' (Daniels 2008: 341fn7)
} 
As section III will show, this seems at odds with normal professional practice since such nonpublic reasons are commonly included in doctors' and patients' deliberations regarding health in ways which determine and justify decisions. For now, note that in the requirement that religion be excluded from deliberation about resource allocation, Daniels' position may also be at odds with Rawls' 'proviso' which allows for religious views at the level of democratic debate and thus, by implication, patient-professional discussion. (Rawls 1997: 783-787) The proviso, however, would not allow religious reasoning to have justificatory weight. On Rawls' view, public reasons must in due course be provided that are sufficient to justify decisions. Given this, the proviso does not resolve the problem which we will now consider, namely indeterminacy. It is the indeterminacy of public reason in healthcare which, if demonstrated, would cast doubt on Daniels' position.

\section{Indeterminacy and healthcare}

If consensus public reason is indeterminate within at least a range of healthcare matters, then this indicates it may prove inadequate to provide a stable basis for justifying decisions about a matter of basic justice. This would render Daniels' approach, especially the AFR procedure, less attractive. The following discussion argues towards this conclusion by considering concrete aspects of healthcare.

Indeterminacy: the case of death

Healthcare deals in fundamental questions of justice, of what is owed to people in respect of their lives and deaths: for example, whether a specific treatment which bears directly on a group or individual should be offered in the first place, continue or be withdrawn. If public reason cannot justify any policy on some basic matters of people's existence, then it leaves irresolvable matters which require decisions. Note that the charge here is not that public reason reaches inconclusive results nor outcomes which are merely unpalatable to those with liberal values but that public reason is indeterminate on fundamental matters of justice.

Jeremy Williams argues that consensus public reason is characterised by such indeterminacy concerning the definition of death. His critique is a version of the incompleteness objection, two forms of which he distinguishes thus:

public reason is indeterminate when it provides...insufficient reasons to justify one's venturing to choose in any way from among the relevant policy options, and inconclusive when citizens find that they have sufficient reasons to adopt their various competing policy preferences, but public reason cannot bring them into agreement regarding which is best justified by vindicating any option beyond reasonable doubt. (Williams 2017: 22)

Indeterminacy is much more threatening to consensus public reason's plausibility than inconclusiveness. For it means that no public reason can be given to people to justify the selection of a policy which would govern a matter of basic justice. Vital areas of political life would not be governable by public reason. If there is no 'viable, non-metaphysical form of reasoning... [about such matters]...that is generally available to Rawlsian deliberators' (Williams 2017: 8) this would be a reason to doubt public reason's completeness.

This matters for healthcare professionals and patients. In Williams' example, 'public reason will inevitably be called upon to resolve the problem of how death is to be legally construed.' Death is a 'fundamentally political' (Williams 2017: 5) matter since death ends the rights and duties of citizenship. But when is it that death occurs? Controversy centres on whether policies should adopt neurological or cardio-respiratory criteria for death. This effects, for example, the timing of organ 
retrieval for transplant. This controversy is informed by contested science and contentious philosophical, metaphysical and religious doctrines.

For Williams, public reason is ill-equipped to help since it suffers from indeterminacy (not mere inconclusiveness) in justifying the basis on which to define death. Reviewing what he calls 'secular' metaphysical accounts, Williams sees no way for judgment between them which accords with public reason:

To know when someone ceases to exist, we need to know what is involved in her - and our - continuing to exist over time. And that in turn depends on our fundamental nature, or what kind of entities or substances we essentially are. The truth about our fundamental nature and persistence conditions is what theories of personal identity seek to establish. There is, however, no such theory that is or could stably remain non-contentious among Rawlsian reasonable citizens. (Williams 2017: 5)

To expect that biological science resolves a dispute within theories of personal identity is to rely on a metaphysical thesis that some citizens will reasonably deny. To coerce the latter on those grounds, therefore, would...be a violation of the terms of public reason.' (Williams 2017: 14) ${ }^{12}$ Scientific evidence may provide data to inform the dispute but it cannot reasonably be expected that such data will resolve it even over the long-term. (Williams 2017: 12-13) In any case, in the meantime, policies and decisions about individuals are required.

With public reason indeterminate between policy options, Williams reviews the 'rather more unusual and unappealing procedural mechanisms' (Williams 2017: 6) for resolving the issue which Schwartzman details in circumstances like this. (Schwartzman 2004: 209-214) He concludes that since 'random adjudication is the only available way to proceed while maintaining independence from comprehensive justification, this is what consensus liberalism requires.' (Williams 2017: 25) That determinations of death be reached by coin flips seems intuitively absurd policy. For example, it would entail that some patients with advanced dementia, whose personal identity is in doubt and whom public reason cannot judge to be among either the living or the dead, should be determined to be either alive or dead by whether a coin comes down heads or tails.

Even if one accepts Williams' case on death, perhaps, given long enough to gather new information and identify appropriate public reasons, other instances of indeterminacy should be reckoned to be very rare or even non-existent. ${ }^{13}$ However, I think indeterminacy is not so rare, at least in healthcare. To see this, consider initially the effects of indeterminacy regarding death's definition. ${ }^{14}$ Significant resources are necessary to maintain the life of members of the human species suffering (e.g.) brain-stem death. This usage is unjustifiable if these beings are not persons, a question about which public reason cannot adjudicate. Whether someone is alive or dead affects justifications concerning the withdrawal of Clinically Assisted Nutrition and Hydration (CANH) from human entities with severe brain injuries or in advanced stages of neurodegeneration. Withdrawing CANH from those who have not expressed, and are now irretrievably (so far as is known) unable to express their opinion on withdrawal, must be justified somehow. But what categorisation should be given to the event whereby CANH is withdrawn? It could not be an act of killing, letting die or a refusal to provide basic care if there is no longer a person present. Similarly, should the removal

\footnotetext{
12 Distinguishing 'between understandings of the conditions under which life remains worthwhile' and then preferring one such understanding will also violate public reason (Williams 2017: 17).

${ }^{13}$ Schwartzman worries that 'the view that public reason is indeterminate is potentially self-fulfilling' since some people 'will have an incentive to cut short the search for a publicly justifiable conclusion.' (Schwartzman 2004: 207)

${ }^{14}$ Williams notes the problems with organ transplant but goes little further (Williams 2017: 4).
} 
of nutrition and hydration or the underlying disease be classified as the cause of death? About these matters public reason is indeterminate.

This naturally matters to individuals but also on a population level. Consider whether it would be legitimate for a public authority responsible for determining health spending for a defined population to justify the denial of publicly funded access to a healthcare resource (e.g. a lifeextending cancer treatment benefitting a defined cohort of citizens) because its cost would reduce the availability of life-sustaining treatment for those suffering brain-stem death and long-term neuro-degenerative conditions. This denial of access would affect or even end specific cancer patients' existence. Considering its publicly binding effect, public reason should be able to account for the legitimacy of the decision's justification.

One problem for public reason is that eligible justifications would rest on the epistemic impressiveness of prognostic claims concerning both sets of patients. If Williams is right, however, the fundamental problem is that justifications must rest, explicitly or implicitly, on non-public theories of personal identity concerning whether patients suffering brain-stem death or advanced dementia are living or dead and, therefore, proper or improper recipients of public funding. Some may think them dead since they cannot engage meaningfully with others or form rational projects. But such a view will have no hope of being a public reason acceptable to all. (Williams 2017: 19) Public reason cannot justify a decision either way on this resource allocation matter without taking a stance on inherently contested questions about human status, human agency and concomitant professional responsibilities. According to the distinction discussed above, public reason is not merely inconclusive on these matters but is and must be indeterminate.

Therefore, another route towards justifying and determining action will be required. At least in the case of death and its ramifications in resource allocation, it seems plausible that 'non-public' reasoning, including religious reasoning, may have a legitimate role in justifying individual decisions and policies covering similar cases. For this matter at least, professionals need routes to justifying decisions which are not governed by consensus public reason.

The extent of public reason's indeterminacy in healthcare

The extent to which what is true of death's definition holds for other healthcare matters is now the question. The answer here is that, in a range of healthcare matters, religious and other comprehensive reasoning may have legitimate and beneficial roles throughout various levels of deliberation and decision-making which Daniels argued, on public reason grounds, should be free of such reasoning. Each of the following three aspects of healthcare indicate public reason's indeterminacy, making the case for a different conception of medical professionalism, the focus of Section III.

\section{(i) Gender transition treatment}

First, public reason must be indeterminate on whether gender transition treatments should be publicly funded. Laborde argues that in various controversial issues - abortion, marriage, freedom of religious associations to discriminate in employment practices - different 'social ontologies' are at work, between which public reason is incompetent to judge. 'Social ontology' here does not mean anything metaphysical but is a term 'establishing what exists in the social world... rooted in social interpretations of...institutions and relationships' and 'claims about the nature of the particular groups and relationships that individuals form.' (Laborde 2018: 43)

Consider how this argument affects whether a public reason could be given to justify public funding of gender transition treatments. Laborde rightly observes that no one should deny the 
'political equality of LGBTQ citizens.' (Laborde 2018: 40) However, there seem to be controversial 'social ontologies' which distinguish the T from (at least) the LGB. There is no theory available to Rawlsian deliberators that, bearing in mind the distinction between inconclusiveness and indeterminacy, 'could stably remain non-contentious' (Williams 2017:5) concerning gender and sexual identity - how being male or female (or neither) should be conceived, still less the meaning or probity of people transitioning between one gender identity and another. If so, then it would not be possible to produce a public reason that could stably remain non-contentious among all citizens such that they either endorse or reject state funding for treatments which aid transition from one gender identity to another.

Other arguments could be adduced for deciding in favour of such funding and perhaps would prevail. But they should not claim the alleged neutrality of public reason nor that dissenting opinions are necessarily unreasonable or anti-egalitarian. As Laborde argues, both Catholics and liberals believe in equality but have adopted different reasonable positions on 'equal marriage', rooted in rival, disputable social ontologies. ${ }^{15}$ The same argument applies to rival social ontologies on transgender identity: it is not equality which is in dispute but the nature of human sexual identity. Consensus public reason must, therefore, first carefully notice and then rigorously absent itself from disputes about questions of 'ontology' concerning which it is necessarily indeterminate and thus about which it is incompetent to adjudicate. ${ }^{16}$

\section{(ii) Abortion and IVF}

Second, public reason must be indeterminate concerning policies which involve allocating public healthcare resources towards certain means to enable or terminate pregnancy. Whether or not the use of IVF technology, which routinely requires embryo wastage, should attract state funding cannot be stably resolved by public reason because of the deep, metaphysical dispute about the status of conceived human life, whether located in vitro or in utero. There could not be public reasons on hand which would enable 'justified acceptance or rejection' of such policies. (Gaus 1996: 153) Similar arguments apply to state funding for terminations, at least in very many circumstances.

Daniels' argument witnesses to this problem. Regarding abortion provision, he claims that divergence from the 'baseline' of normal functioning is not

a necessary condition for including a medical service among those we owe each other. Our obligation to protect the equality of women requires us to cover nontherapeutic abortions in public or private insurance schemes. But this rationale clearly goes beyond the primary rationale, since an unwanted pregnancy is not a disease or disability; viewing it as a medical necessity is thus inappropriate. (Daniels 2008: 149-150)

The phrase 'goes beyond' must mean 'is different from', thereby distinguishing normal species functioning from an additional justification, the 'obligation to protect the equality of women.'

\footnotetext{
15 Reasons of space prevent detailed discussion of religion and equality (see Waldron 2017) For discussion of Waldron's view of religion's role in public discourse see Laborde 2017: 126-128.

16 Someone might think that consensus public reason can be determinate here but only by producing a result which is unpalatable to those adhering to liberal values. Perhaps, they might say, consensus public reason cannot justify a decision to allocate any resources to gender transition medicine because there is no evidence to support its use that can be admissible in public reason. That being the case, and since we should not allocate resources to medical treatments unless there are public reasons in favour of doing so, rejecting such an allocation in this case is a public reason determination. However, this is not my argument. What counts against such an argument is that the nature of evidence of benefit in this case is liable to change and, crucially, will inevitably involve significant dispute as to what constitutes benefit. In contrast, my argument is that a judgment on gender transition treatment involves essentially endorsing or rejecting contested notions of human personal identity between which consensus public reason must be indeterminate since there is no possibility of a stable consensus on the matter.
} 
Daniels' claim involves importing into the equality of men and women (which is indubitable) a normative view of what said equality requires (which is highly controversial, for reasons which are at least partly metaphysical in nature). For it must include within it a claim about the status of the embryo or foetus which depends upon a comprehensive view by which other citizens should not be bound. ${ }^{17}$ This also applies to embryos conceived for IVF purposes, at least in cases where not all embryos are subsequently implanted, and still more so for embryos conceived solely for research purposes. Rejecting the possibility of public reason justifications does not mean that all abortion or IVF treatment should be prohibited but only that public reason can afford no basis to decide one way or another, except arguably in cases when the very continuance of the mother's life is threatened unless a termination is performed. ${ }^{18}$

Since public reason is indeterminate as to policy governing the vast majority of circumstances regarding abortion and IVF, a proscription of religious reasoning from justifications for decisions in favour or against state funding of IVF procedures or terminations is unwarranted. People may or may not find themselves persuaded by such reasoning. However, there is no theoretical reason to think that binding decisions, covering very large classes of cases, could practically be reached without recourse to what consensus public reason calls 'non-public' reasons. Therefore, citizens are not necessarily disrespected if those arguments are advanced or indeed taken to justify decisions publicly.

Consensus public reason thinkers will naturally be sceptical of this move. Andrew March suggests an alternative, far narrower role for religious reasons in public justification of healthcare resource allocation. He believes he has located 'principled grounds for democratic citizens to distinguish between religious arguments on the question of sexual equality and religious arguments on the question of social justice.' (March 2015: 116) On the one hand, he thinks religious reasoning is legitimate for justifying 'proportionate financial contributions to public institutions' (March 2015: 115) to support universal access to healthcare. On the other hand, such reasoning is illegitimate where it involves 'paternalistic or authoritarian attempts to discipline, exclude, or disadvantage individual lives'. (March 2015: 121) Examples include justifying 'subsidies to religious [healthcare] organizations for sectarian religious goals' (March 2015: 114-115) and arguing against legal recognition for same-sex marriage or the provision of 'birth control'. (March 2015: 121)

A deficit in March's account compared to Daniels is that he does not pursue implications for the justification of resource allocation within healthcare. March's claim in support of his distinction between legitimate and illegitimate religious reasoning is that universal access to healthcare is different than issues bound up with paternalism and authoritarianism because, in healthcare, 'the political demand at stake is other-regarding.' (March 2015: 115) However, this is not a sustainable distinction, largely because of the inextricability of questions of sexual equality with health services. Public reason's indeterminacy regarding transition treatment, abortion and IVF show that issues of human status and sexual equality bear together upon healthcare resource allocation decisions such that it is impossible to maintain March's distinction.

The underlying problem with March's analysis is that healthcare is not 'other-regarding' in a way that distinguishes it from opposition to legalising same-sex marriage. Laborde distinguishes

\footnotetext{
17 Similarly, while Nussbaum's account of capabilities offers a powerful argument regarding the specification of human equality in respect of reproductive rights (e.g. Nussbaum 1999: 235) her claims' authority rest on the contestable social ontology regarding women and pregnancy of the 1994 International Conference on Population and Development, which again cannot remain stably non-contentious among Rawlsian deliberators.

18 A policy covering such life-endangering cases could be settled by reasons which are acceptable to all without recourse, in public justification, to 'non-public' reasons. See Schwartzman 2004: 203-4 for discussion of this point.
} 
'Catholic marriage' from 'liberal (equal) marriage' not as unreasonable and reasonable in public reason terms but by their distinct social ontologies. Liberals advocate a specific social ontology of marriage as not defined as 'a unit of natural social reproduction.' (Laborde 2018: 39) Catholic doctrines of marriage are other-regarding, but just not as liberals would like them to be. Similarly, justifying the utilisation of a limited public resource for abortion, IVF or transition treatment involves essentially contested questions of what is involved in being other-regarding. To rule out religious reasoning from those matters on public reason grounds would be to deny to other citizens the use of their taxes (e.g. for a cancer treatment) on the basis of a contested social ontology of who 'others' are. Disputes irresolvable by public reason surround the status of embryos and foetuses (and the level of protection they are afforded vis-à-vis pregnant women) or, in the case of transition treatment, whether the sexed identity of each person is assigned or recognised at birth (or, indeed, in utero).

March observes that religious argumentation may contribute to societal debate about how to understand 'fetuses and other future persons' (March 2015: 118, cf. 104) but fails to follow through the healthcare implication, namely that taxpayer-funded abortion provision makes a determination for which public reasons acceptable to all cannot be given. ${ }^{19}$ In these cases at least, seeking to resolve resource-allocation problems using non-public reasons cannot be simply ruled out as unwarrantably paternalistic, considering both public reason's indeterminacy on these matters and the resource constraints within which healthcare operates. March's analysis thus fails to recognise the difference which religious reasoning might make to the justification of what should be available to access within universal healthcare provision. By contrast, a Catholic commitment (for example) to universal access to healthcare may have specific resource allocation significance: universal solidarity includes solidarity with the unborn and those suffering from irreversible dementia because all these are counted as human persons.

\section{(iii) Risk and responsibility}

Even if the matters discussed so far were recognised as indeterminable by public reason, it could be that the rest of healthcare policy is not indeterminate and suffers, at the worst, from inconclusiveness. This third argument is intended to indicate how indeterminacy is likely to be present across many different areas of healthcare policy. In this, the charge of indeterminacy is plausible but the extent of its applicability is harder to prove than in the cases just discussed. This part of the argument is therefore more exploratory and pursued in more detail.

The claim is that public reason seems likely to be often indeterminate between policies which concern what should be done and by whom to protect against risks of ill health. What account of responsibility to protect against risks should policies adopt? Consider Daniels' category of 'unprotected risk'. ${ }^{20}$ There are those who lose out when a certain risk, which they judge should be covered (e.g. by insurance or a national health service), is left uncovered. Daniel thinks they should be given reasons for this loss which are acceptable to all.

Risk seems a more difficult category for public reason than Daniels supposes. ${ }^{21}$ We cannot protect against all risks. We choose to protect against some risks. On Daniels' scheme, a risk will remain unprotected if such protection cannot be publicly justified. Any decision to protect against any specific risk depends, therefore, on commitments about what it is publicly justifiable to protect. Consider again the definition of death. If a health service chooses to protect against the risk of

\footnotetext{
19 On this point see Williams 2015: 38-40.

${ }^{20}$ Daniels speaks of such a risk as 'appropriate or even medically necessary' (Daniels 2008: 108).

${ }^{21}$ In Just Health, Daniels does not provide an integrated account of AFR and risk. The only sustained treatment concerned the infection risk to professionals, especially amidst a pandemic (Daniels 2008: 221-229).
} 
brain-stem death by committing to pay for permanent care for those who enter such a condition, then it takes a stance on a matter about which public reason must be indeterminate.

The claim is that this difficulty with risk will be routinely replicated across many areas of health policy. Take, for example, the heightened risk of 'autosomal recessive genetic disorders among births in populations where consanguineous marriage is customarily practised compared with those in which reproductive partners are typically unrelated.' (Salway et al 2019: 1) In the UK, marital consanguinity is especially practiced among those who identify as 'British Asian/Asian Pakistani'. (Salway et al 2019: 18) Studies show that 'the incidence of any congenital anomaly is typically two to three per 100 births among unrelated couples compared with five to six per 100 births among first cousin couples'. (Salway et al 2019: 1) This incidence gives rises to costs to be borne by the population as a whole. ${ }^{22}$

Parallels 'have been drawn with the rising age at childbirth among well-educated White British women and the associated increased risk of chromosomal disorders. Why...does one cultural practice attract condemnation while the other has prompted developments in foetal testing, patient education and service delivery?' (Salway et al 2019: 2) Much debate has followed the relative allocation to support these cohorts, with the former often subject to pejorative media treatment and less focussed healthcare provision.

How should a policy address the risks presented in these two cohorts? In particular, should part of the rationale for tax-payer funded protection of the risk of genetically disordered children be that public resources be expended to discourage consanguineous marriages, at both personal and population levels, on account of the risks and the associated long-term costs? If so, should resources also be similarly expended to counter the rise in age at which some women are becoming parents? Such policies would suggest that such behaviours are irresponsible, when compared with other alternatives.

These are highly controversial societal questions about which it may be thought that public reason could realise an inconclusive result between rival policy options, all justified by public reason. However, the matter in fact seems indeterminable by public reason. No public reason acceptable to all could be provided to justify any policy on this matter. What is reasonable regarding risk and benefit is just not the kind of thing public reason can resolve to the satisfaction of all reasonable people. What is beneficial is bound up with highly contested social ontologies, contested, comprehensive visions of the good. Moreover, the perception of what constitutes the risk of harm will be read in terms of what is counted as beneficial.

Consider the question of whether discouragement of consanguineous marriage could be publicly justified. It seems that a decision to use healthcare resources to discourage consanguineous marriage could not be presented in any way which is acceptable to the communities which practice consanguineous marriage. Instead, the suggestion that this practice is irresponsible would be felt as an attack on a core feature of cultural identity. This is not a speculative observation. It has been tried before and the results were highly counter-productive. (Darr 2016: 66) This matters because the policy would be least likely to be acceptable to those for whom protecting against the risk of genetic disorder is most important and who, as Daniels says, would be the biggest losers were this risk to become unprotected or only partially protected, a distant but not impossible scenario.

22 'Of an estimated 2,300 children born annually with a severe recessive disorder in the UK at least $690(30 \%)$ are from parents of Pakistani origin. They contribute $3.4 \%$ of births but have $30 \%$ of UK children with recessive disorders. About a third of the affected children die before five years of age. Most of the survivors suffer chronic disability, and are cared for by community or specialist paediatric services.' (Darr 2010: 2). 
On the other hand, if there is a policy choice not to discourage consanguineous marriage, then this cultural practice functions in effect as an unchallenged 'non-public' justification for the use of public resources. The choice not to discourage consanguineous marriage is a choice to accept the 'non-public' rationale that the risk be protected: namely that the benefits which accrue to a community and individuals through consanguineous marriage justify the public resource spent to manage the effects of that community practice which occur in children conceived and born with genetic disorders (e.g. through pre-marital and community education about risk). Part of the public rationale for protecting against the risk would lie in the benefits of the practice, as understood by the beneficiaries. As we shall see shortly, this is in fact the way that recent research and practice have proceeded. The important point for now is both that public reason is indeterminate on the matter and 'non-public' reasons function as justifications.

The underlying reason for indeterminacy here are the social ontologies at work. What is thought, in Daniels' phrase, 'appropriate or even medically necessary' is interpreted via reasoning about the risks and benefits of practices as understood by individuals and communities. In respect of the British Asian/Asian Pakistani community, while 'Islamic faith is not the prime reason' for consanguineous marriage, the reasoning underpinning the practice is nonetheless inadmissible in consensus public reason:

Marriage within the family strengthens family ties and support systems, maintains a woman's status within the family hierarchy, facilitates the finding of suitable partners for both men and women, and maintains the family lineage. Marriage within the family also preserves culture and traditions that might otherwise be lost by people who no longer live in their native country. In addition, there may be financial benefits since marriage to relatives helps to protect family wealth and property for future generations. (Khan et al. 2010: 74)

This reasoning is inherently 'non-public' and quite different from the social ontology which surrounds the rising age of childbirth among 'well-educated White British women', which represents a more diffuse but arguably also comprehensive doctrine about the benefits of freedom of reproductive choice. In either case, the perception of risk and therefore the justification of any protection will inevitably be interpreted in terms of benefits sought by individuals and communities. What is valued provides the rationale for a willingness to bear with certain risks, even if it imposes significant costs on others justified for non-public reasons. ${ }^{23}$ This contest about values, embedded in social ontologies, seems intrinsic to the issue of genetic disorders proceeding from consanguineous marriage and therefore a matter which is indeterminable by public reason. ${ }^{24}$

\footnotetext{
23 This integration of risk and value is in tension with Daniels' account of 'well-being' (Daniels 2008: 125).

${ }^{24}$ An anonymous reviewer has suggested that certain assessments of risk and benefit are simply unreasonable, that consanguineous marriage is a practice which embodies just such an assessment and therefore that such an assessment should be ignored in public discussion. If this is so, then whatever response a health service offers to the practice is secondary to the primary political judgment that the reasoning behind the practice is inadmissible in resource allocation decision-making and, arguably, that all reasonable people could accept a legal ban on consanguineous marriage. Whether or not a ban is actually what public reason would require, the key problem with this argument is that it assumes that a standard of reasonableness is available whereby consanguineous marriage may be judged unreasonable: presumably that it is reasonable to avoid the doubled risk of congenital abnormalities and unreasonable not to avoid it. However, any such standard which is stably non-contentious among reasonable people seems impossible to attain because of the highly complex interplay between benefit and risk in which individuals and communities engage. Moreover, a charge of cultural imperialism would be likely to stick unless there was a policy to encourage early childbearing among women and discourage childbearing among older women, or even (even less plausibly) a ban on childbearing above a certain age when perceived risks outweighed perceived benefits. A question to be faced is why the significantly heightened risks which accompany pregnancy among older women would be thought reasonable if consanguineous marriage were judged unreasonable.
} 
In practice, recent UK recommendations are to invest considerable resources not in discouraging consanguineous marriage or in treating those entering such unions as irresponsible but in sensitive, educational, clinical conversation aimed at informing people about risks and choices so that they can take responsible action in line with their values. In particular, it is recommended that resources should be invested in training professionals to provide 'culturally and religiously competent, nonjudgemental care'. (Salway et al 2019: 20) This policy process itself required careful deliberative engagement in how recommendations would be received by relevant communities. It accepted that the nature of the risk is not abstract but embedded within the social ontologies not only of relevant British Asian populations but also of white populations where customary consanguineous marriage is commonly practiced. The way that the recommendations emerged and the nature of the recommendations suggest that a community's cultural mores, reasoning and beliefs are in effect justifying the resource allocation decisions. To claim that that the public justification is respect for those features of a community's life is to offer only a very limited description of the issue. In practice, in individual professional conversations as well as in policy recommendations, there is a decision to accept those practices rather than in any way criticise them.

There is, it seems, some inevitable policy indeterminacy associated with consensus public reason when it comes to interrelating benefits and risks. How policy is formed regarding a cultural practice followed by various UK ethnic minorities and by very large numbers of people globally is in practice very different from what public reason requires. Were there space, similar arguments could be applied to how various communities engage in different policy areas in order to ascertain the extent of indeterminacy. For example, views about ageing are culturally diverse, underpinned by varying religious and cultural traditions. Should old age be treated as an individual risk for which individuals are responsible or a community opportunity to take responsibility for and honour elders? Should older people be required to isolate to avoid the risk of contracting a pandemic virus or should they be permitted to make up their own minds as to the size of groups in which they will mix? Answers will draw upon quite different views of human life found within a plural society, such that determinacy by means of public reason seems highly unlikely. Debate about the kind of provision appropriate and necessary for people as they age will struggle to settle on a policy justified by public reasons, largely because of divergent forms of valuing the phenomenon of old age.

One public reason response could be to locate a basis for policies (e.g. for discouraging consanguineous marriage or encouraging healthy ageing) in a political account of responsibility. Such a policy could specify that it is irresponsible to bind one's fellow citizens to costs by engaging in practices, however beneficial to oneself, one's family or one's community, which have more risk of leading, for example, to the conception and birth of children with significant genetic disorders, unable to enjoy the normal opportunity range; or to a high-cost old age. Daniels notes the 'opportunity for welfare or advantage view' regarding risk, namely that if 'we have made certain choices - undertaken certain options - that have risks that we were or should have been aware of, then others do not owe us assistance' (Daniels 2008: 72) or at least we are not 'owed (full) compensation or (as much) assistance by others'. (Daniels 2008: 156)

Daniels rejects any such approach because identifying causation and therefore fault is too difficult. (Daniels 2008: 155-157) However, this is not argued in any detail. He only cites the case of childhood obesity, claiming that it is wrong not to give treatment to a boy who becomes fat after eating fries rather than fruit. (Daniels 2008: 157) This brief reference underplays an important discussion and stands in stark contrast to the much more precise ways in which, for example, competent adults can engage in making informed reproductive or pre-operative choices. ${ }^{25}$

25 The disagreement between Daniels and the opportunity for welfare view is significant, especially when combined with Daniels' relative silence on responsibility (see below). It indicates the depth of controversy and perhaps 
Another public reason response might be that responsibility is irrelevant to healthcare resource decisions. Indeed, Rawls is largely silent on individual responsibility for health. (Daniels 2008: 7477) Daniels admits that his 'extension of Rawls says nothing about the corresponding issue of responsibility for health' (Daniels 2008: 72) though oddly also thinks that some people (e.g. smokers) lack the agency to make responsible decisions. (Daniels 2008: 198) The UK resource allocation body (NICE) appeals to Daniels' AFR procedure and rejects a focus on personal responsibility, largely on account of the difficulty of doing so accurately. (NICE 2008: 7 \$4.1) ${ }^{26}$

This cumulative silence, confused messages or rejection of personal responsibility may present a worry for the completeness of public reason, in particular whether there could be a political account of responsibility for health, acceptable to all, 'presented independently from comprehensive doctrines of any kind'. (Rawls 1997: 776) Denying the relevance of responsibility to resource allocation decisions is not obviously a position which can be stably accepted by reasonable people. It would require that losers, on Daniels' scheme, should be satisfied with there being no requirement for an assessment of winners' responsible use of resources. This would seem hard to justify to prospective organ recipients who follow medical guidance but missed out to those who did not, especially if it became more technologically possible to ascertain patient adherence. If the requirement is simply that recipients be medically fit, regardless of how well they have prepared pre-operatively or plan to live post-operatively, this itself communicates a message about personal responsibility which seems hard to justify in terms of public reason.

Indeterminacy in respect of responsibility is evidently not as clear-cut as in the definition of death. Yet when responsibility is connected to how choices intersect with culturally embedded attitudes to risk and value, as will commonly be the case in a plural society, it seems hard to identify what public reasons for any policy choice all deliberators could reasonably and stably accept. In short, this seems more likely not to be a matter of inconclusiveness but rather of there being no good public reasons for choosing any policy. What risks are worth protecting because valuable and whether people should be held responsible in a manner which affects allocations seems inevitably linked to contentious, non-public reasoning about, for example, free will, determinism and human agency. Similarly, what compassion requires of a community towards those who act irresponsibly is certainly non-public, with no viable path to determinate policy without recourse to reasons which could not be acceptable to all. ${ }^{27}$

In summary, in each of (i)-(iii), utilising consensus public reason leads to an indeterminacy about policies. Just as consensus liberalism will be indeterminate on policies regarding death's definition so it appears to be indeterminate in these matters. This is more certain in (i) and (ii) but has plausibility in (iii) especially in relation to community practices and with likelihood in relation to a doctrine of responsibility. My argument on the extent and implications of consensus public reason's difficulties suggests the need for more enquiry into the extent of indeterminacy than is possible here. However, to discount religious reasoning as lacking 'relevancy' to public decisions on these matters is to rely unwarrantably on the availability of public reasons.

\section{Medical professionalism}

\footnotetext{
insurmountable difficulty of arriving at determinate policy regarding responsibility for health by means of consensus public reason.

${ }^{26}$ For commentary see Rumbold et al. 2017: 115.

27 Martha Nussbaum seeks to provide an account of compassion which could be adopted by all (Nussbaum 2001). However, her view installs a further comprehensive account of reality, rooted in Attic tragedy (Hordern 2020: chapter 5).
} 
The argument of section II has suggested the need for alternatives to public reason in deliberation concerning healthcare resource allocation, with particular attention to medical professional practice. ${ }^{28}$ Doctors typically reckon that 'non-public' beliefs have a legitimate and potentially beneficial in justifying resource allocation decisions. The practice of sensitive conversation with individuals and communities regarding how the risk of recessive genetic disorders relates to their beliefs and cultural practices is a case in point. As this example shows, 'non-public' reasoning is permitted to determine not only individual cases but also policy concerning classes of similar cases, specific groups (e.g. religiously or culturally defined subpopulations) and the population at large. This is one instance of the wider trend towards patient and public involvement in policy-making and research in which patients' perceptions of risk shape decision-making.

Daniels presents public reason as dealing competently with healthcare at all these levels of decision-making and in the interaction between the levels. Failing in this task would render its plausibility as a practicable theory in doubt. The focus here is on Daniels' public reason constraints on professional practice. The nature and role of medical professional judgment is central. Williams observes that a decision to count as non-citizens - because 'dead' - those entities with advanced dementia would constitute a 'conspicuous breach with prevailing considered moral judgements'. (Williams 2017: 19) In practice, healthcare professionals, at least in publicly funded health services, operate in a public capacity and so their judgments are particularly important. They have authority and discretion, circumscribed by guidelines and law, to determine the disposal of coercively collected public resources, not only regarding individual patients but regarding whole populations. Their work routinely requires making judgments about care appropriate for individual patients and for classes of relevantly similar patients (e.g. all those with similar neurodegenerative conditions, all those seeking transition treatment, all those in consanguineous marriages). They increasingly do so in partnership with such patients.

Doctors may have some responsibility for making healthcare resource allocation decisions and policies concerning a national population or some specific regional subpopulation thereof (e.g. within a Clinical Commissioning Group (UK), a public hospital or district authority). Their professional judgment, forged through engagement with individual cases, clinical evidence and professional culture, affects policies shaping practice for whole classes of similar patients, across a hospital, region or nation. Decisions and policies at each of these levels will in turn affect the range of healthcare options open to citizens. The question is what reasoning should be included or excluded in deliberation and justification for such decisions and policies.

\section{Consent and collaborative deliberation}

Consider, first, deliberation at the individual doctor-patient level. Consensus public reason would constrain medical professionals' reasoning, concerning the disposition of public resources coercively denied or permitted to a population, from including 'non-public' reasons in justifications for decisions. This applies, on Daniels' account, at this individual level. However, the screening out of non-public, especially religious reasons from individual patient care is at odds with widespread professional practice. Professional practice and literature on 'collaborative deliberation' provides an approach to determining and justifying the use of public resources which incorporates such reasoning. (Elwyn et al. 2014)

In such deliberative practice, the policy is that the personal significance of health concerns, inflected by patient values, practices and beliefs, including religious reasoning, may be taken

\footnotetext{
${ }^{28}$ This discussion is restricted to doctors/physicians but could be applied to other health/care professionals and multidisciplinary teams.
} 
account of in a justification for an allocation decision. Patients are conceived as being on an 'existential journey' within which such factors weigh heavily in determining next steps. (Gulbrandsen et al. 2016: 1509) The UK General Medical Council guidance is that in 'assessing a patient's conditions and taking a history, [doctors] should take account of spiritual, religious, social and cultural factors' but 'must not put pressure on a patient to discuss or justify their beliefs'. (General Medical Council 2013: 5 \$29) This does not rule out an exchange of perspectives where it may be helpful. Just what 'take account of means is not closely specified but is left open as a matter for determination.

These factors matter for the nature and practice of consent. To give informed consent, a patient must have sufficient understanding of the treatment, test or examination being offered and a willingness to receive it based upon that understanding. Consent requires clinicians to communicate about risks, benefits and alternatives. But the communication of bare information inadequately describes the doctor-patient encounter and the justification of any decision to consent. Rather, the consent process requires an understanding of the significance to the patient of this information. In law, that significance is reckoned not according to a reasonable body of medical opinion, nor according to what a reasonable person would think, but according to what is reasonable for this person. In this sense, doctors are to 'take account of' a patient's outlook on life, what benefits are important to them and what risk of possible or actual suffering any decision might involve. ${ }^{29}$ A patient's religious beliefs would be one such outlook, embedded in a social ontology in Laborde's sense, by which a patient - and perhaps their family - interprets information about the risks and benefits of any decision. While no pressure should be placed on the patient to discuss their beliefs, they may well choose to do so.

Moreover, within the consent process, it is often useful for doctors to make explicit the interpretation of the risks which guide their recommendations. They may draw, for example, on population level health information and their considered judgment of what is valuable and morally relevant about specific courses of action. This makes for a more transparent discussion with a patient who can articulate, if they wish, their perception of the risks, values and moral concerns involved in a decision. The professional's understanding of the patient's outlook on life and what is important to them may then become interwoven with the justification of doctors' advice and recommendations.

This consent process may be categorised as an aspect of compassionate imagination, whereby patient and professional come to a sensitive appreciation of each other's perspectives. (Hordern 2020: chapters 3 and 6) In public reason terms, this process has a surface similarity to one in which 'non-public' reasons are considered alongside other reasons and may prove decisive. However, the non-public reasons are not simply on one side or another. For example, a doctor's considered judgment may be that those suffering brain-stem death are not dead. More generally, the interweaving of the doctor's imagination with the patient's perceptions of risk and value, and the patient's circumstances, often very vulnerable, mean that the process is best described as a form of partnership between patient and doctor. For 'collaborative deliberation', patient or doctor may take turns to lead and so determine direction on the next steps of a patient journey. (Elwyn et al. 2014: 163)

Consider a patient rejecting the use of resources for a termination for religious reasons in the case where a continued pregnancy would likely lead to significant danger to her health and the birth of a child who would either not live long outside the womb or be severely disabled. This may in turn require a heavy deployment of public resources both in the child's birth and over the course of

${ }^{29}$ For risk communication and law in UK healthcare see Tweedie, Hordern, Dacre 2018: p.28; also Herring et al. 2017. 
both the mother's and perhaps the child's life. A policy which permits this course of action implicitly or explicitly takes a stance in favour of a highly contested doctrine about the status of unborn life in justifying decision-making. To claim that the reason which justifies the decision is respect for patient autonomy is only partially to describe the actual decision and consent process. This process is inextricably linked to the patient's 'non-public' view of in utero life as it bears on the interpretation of the risks as they are presented to her. Crucially, it misses the rationale of policy and guidance for professionals which explicitly encourages doctors to collaborative deliberatively with and not abandon patients, engaging sensitively in the patient's perceptions of risk and value, based perhaps on their religious beliefs, in order to determine with them the course of action.

A doctor may, without any necessary difficulty, collaborate with a patient in enabling their religious reasoning to constitute a justification for such a decision, whether or not the clinician shares the religious reasoning. Indeed, a doctor may have to agree to decisions they think are seriously unwise, such as the continuance of pregnancy in this kind of case. Here the religious reasoning is close to being a trump. However, such a metaphor inadequately describes the partnership-based rather than adversarial nature of the decision-making.

Moreover, where it will do no harm, a doctor's religious belief may be part of the deliberative process, and transparently so, especially where it accords with a patient's religious belief (e.g. that unborn life should not be terminated in this kind of case). This practice, of doctors sharing their religious beliefs where appropriate, is permitted by General Medical Council guidance. On the other hand, doctors may withhold agreement on the basis of clinical ineffectiveness or, in some circumstances, religiously-based conscientious objection. In the latter case, the nature of the conscientious objection could be explained on request by the patient. There is discretion here. Some professionals' reasoning should not be transparent in the decision-making process, not because it is 'non-public' but because it is likely to harm a patient. In this case, the articulation of a professional's comprehensive doctrine that an unborn child incompatible with life outside the womb is not a person seems likely to be harmful. But where, in the professional's judgment, harm is not likely, professionals and patients may engage each other's comprehensive doctrinal reasoning - including religious reasoning - in search of compassionate, mutual understanding and a decision, the justification of which may incorporate religious or other comprehensive reasoning. (General Medical Council 2013: p.18 \$54; Hordern 2020a)

Collaborative deliberation, communities and advocacy

Consider, second, how collaborative deliberation applies at the population level.

On the one hand, individual patient-doctor collaborative deliberation will affect other citizens inasmuch as it changes the resource available to others. This may not be apparent in the individual case but becomes clear as individual cases are aggregated. If a large number of patients, working with their doctors, made advance decisions ('advance directives'), for what Daniels would think of as 'non-public' reasons, that they wished to be kept alive for an extended period after they had suffered brain-stem death, this would affect available public resources. Similarly, if numerous individuals decided that they wished to undergo transition treatment, a resource allocation matter about which consensus public reason cannot be determinate, this would have an effect on what other resources are available. Similarly, if a significant cohort of patients collaborated with doctors to reach a decision to freeze embryos in order to postpone parenthood and undergo IVF at a time of their choosing (again, a resource allocation matter concerning which public reason cannot be determinate), this would have a similar constraining effect on others. 
On the other hand, shared decisions may be reached on the basis of collaborative deliberation between medical professionals and those who represent the interests of cohorts of individuals with one or more subpopulation characteristics. A characteristic might be a condition, such as Cystic Fibrosis. It might also be a comprehensive doctrine associated with an ethnic or religious identity. Decisions about individuals' health remain individually tailored. Nonetheless the range of possible choices in which those decisions take place have to be decided upon through deliberation at a population level.

Collaborative deliberation here concerns community participation in the process of justification. For example, if a large number of people determined that the benefits of consanguineous marriage outweighed the risks, and such marriage was not discouraged but rather accepted and its effects addressed, this would have an effect on public resources. For those whose self-understanding involves an essentially corporate identity a refusal, on public reason grounds, to recognise individuals as members of a cohort (or community) is to deny, for no good reason, what is important to them. By contrast, to engage in healthcare allocation deliberation with people in light of their corporate identity may illuminate problems which otherwise are disguised for reasons such as religious illiteracy, discrimination or racial bias. Medical professionalism requires compassionate, imaginative engagement in the beliefs and values of individuals and communities. In light of the barriers posed by religious illiteracy in particular, a high quality of engagement may be easier to accomplish if doctors are themselves community members, both knowledgeable about any mainstream community beliefs and alert to the range of dissenting views and practices which community members may hold.

Doctors thus become partners and advocates for their patients. This may mean that their patients' reasons become the substantive justification for policy, guiding how they accompany one another in ongoing deliberation and decision-making. This participative mode of deliberation does not require any decision-makers to endorse any religious or other 'non-public' reasoning as their own but only the principle that such reasoning may be formative in justifying public decisions about how resources are used. What makes the religious or cultural reasoning formative is that, in becoming shared via the doctor's role as advocate, it determines both how the partnership of the professional with the individual or community proceeds in the deliberative process and the decision itself.

Collaborative deliberation on this community and population level is significantly more attuned to the reality of health needs than consensus public reason. Daniels' account of a doctor as 'Ideal Advocate', governed by the AFR procedure, strips away aspects of human health to which collaborative deliberation, in its advocacy mode, pays close attention. Charlene Galarneau has argued that AFR has an unjustly exclusionary effect on healthcare resource allocation decisions. Daniels' focus on 'the principle of equality of opportunity is asserted to outweigh the multiple and diverse priorities, meanings, and values embraced by multiple and diverse groups'. (Galarneau 2016: 26) On Daniels' scheme, it is 'individuals, not communities or groups, that are granted moral priority or salience'. (Galarneau 2016: 24)

By contrast, engaging with a religious or cultural community's internal arguments may improve healthcare commissioning. ${ }^{30}$ Cultural mores could be relevant where a community's genetics, culture and diet expose them disproportionately to certain conditions. (Watkins et al. 2013) Engaging with internal cultural debates may help to determine policy. Consider a religious context where circumcision is not widely practised and yet could be preventive of HIV. Incorporating the religious significance of circumcision into public policy deliberation and decision-making could

\footnotetext{
${ }^{30}$ Heginbotham criticises AFR's 'unashamedly North American liberal values' (Heginbotham 2012: 94).
} 
lead to resource allocation decisions (e.g. for circumcision operations) in ways which secure deliberative participation, identify the right ways to ensure take-up and so improve health. (Downs et al. 2017; cf. Laborde 2017: 128)

In summary, if public reason suffers from indeterminacy on responsibility, values and risk, excluding religious reasoning where engaging with it might be beneficial, seems unwarranted. (Hordern 2017) Collaborative deliberation in healthcare should permit communities' religious or other comprehensive reasons to be publicly recognised as justifying their endorsement of and participation in a public health policy. By short-circuiting civic curiosity about what religious reasoning might have to contribute, Daniels' consensus public reason removes important public health options. This 'empirical impact' objection to public reason (Billingham and Chaplin 2019: 134-135) allows for the possibility, via collaboration deliberation at a population level, of religious reasoning playing a role in allocation justifications. ${ }^{31}$

This does not require privileging religious organisations since any comprehensive doctrine could play such a role. It does require allowing the incorporation of the beliefs of religious citizens and communities in decisions which affect their health and therefore, by extension, the resources available to others. The healthcare slogan "no decision about me, without me" implies "without taking account of our deepest reasons concerning the significance of our lives and health". Thus justifications for resource allocation decisions affecting subpopulations may legitimately include religious reasoning both to inform the substantive decision about policy and to aid participation. ${ }^{32}$

Medical professionalism and societal debate

Finally, doctors' role as advocates in individual and community-level collaborative deliberation clarifies their role in contested societal debates. Consider again instances of indeterminacy discussed in Section II.

First, comprehensive doctrines about sexual identity which interpret clinical evidence to argue for or against certain forms of gender transition treatment, may be advocated over time by medical professionals. They may do so in alliance or opposition to gender critical theorists, transgender organisations and religious communities and may be found persuasive or unpersuasive in public deliberation. Population-level collaborative deliberation frames this process well. The challenge for those adhering to differing social ontologies concerning transgender identity, is to offer persuasive arguments which carry sufficient support to enable a policy position on the appropriateness or otherwise of state funding for transition treatment.

\footnotetext{
${ }^{31}$ Space prevents exploration of this argument's implications for the social determinants of health. Daniels claims that Rawls unwittingly incorporated the basis for a theory of justice in respect of health all along, though undermined it through mistakes and oversights (Daniels 2008: 13). For Daniels, Rawls' theory of justice accommodates health once healthcare is subordinated to the social determinants of health since 'health status [is] a determinant of the opportunity range. Since opportunity is included in the index of primary social goods, the effects of health inequalities are thereby included as well.' (Daniels 2008: 98-99) However, if one accepts Daniels' interpretation, it is plausible that the possible justificatory role of 'non-public' reasoning which collaborative deliberation requires could permeate many elements of the theory of justice. For religious and other 'non-public' reasoning about the significance of health would have a legitimate role in justifying at least some resource allocation decisions across all the primary goods Rawls had in view. ${ }^{32}$ It is not clear whether or how convergence public reason would address these granularities in health professionals', patients' and communities' interrelationships. A 'convergence justification occurs when a law is justified to every citizen, but different citizens (or groups of citizens) have different reasons to accept it. The law is justified to different (groups of) citizens by different considerations, and there is no one justifying reason that all accept.' (Billingham 2016: 137) Whereas such a convergence account has a formal separation of public justification from public deliberation, 'collaborative deliberation' requires a compassionate, imaginative, evidence-based integration of the two.
} 
Second, over time, a policy supporting doctors' sensitive engagement with communities which practice consanguineous marriage, avoiding discouragement of the practice but focussing instead on education about how to manage the risks associated with it, may contribute to a reformulation of the practice or lower level of participation in it, such that the risk of recessive genetic disorders is decreased in the relevant sub-population.

In such collaborative deliberation, reasoning which justifies a religious person's or community's decision may influence those who either share that religious belief but not that specific reasoning, or hold another religious belief or no religious belief at all. Religious reasoning concerning the determination of death, transition treatment, pregnancy, risk and responsibility, may be found compelling by those not adherent to the religious reasoning in question but whose understanding is reformulated through engagement with that reasoning. This is not 'translation' of religious reasoning into 'secular' reasoning. A Christian and a Muslim may, through conversation, discover shared religious reasons which justify the same resource allocation policy. Equally, just as views may be reformulated through religious reasoning, so too may views be transformed by engagement with non-religious comprehensive reasoning.

Construing medical professionals' collaborative deliberation in terms of advocacy and engagement amidst indeterminacy recognises how their judgment, forged through beliefs, values and clinical expertise, may have appropriate influence, in partnership with patients. Situating doctors' professional judgment as one contributor among others to public argument is an appropriate check on the possibility of an overly deferential culture towards such judgment or a colonisation of medical expertise by one comprehensive doctrine or another. Through this process of societal collaborative deliberation, with professionals in partnership with the people they serve, resource allocation decisions may legitimately and beneficially be justified with the aid of religious or other comprehensive reasoning without disrespect to any. ${ }^{33}$

\section{Conclusion}

In conclusion, if consensus public reason is incompetent to make determinations concerning a key aspect of people's expectations for a just government, namely the provision of healthcare without which people's very existence is severely threatened, this should lessen its appeal. The argument has been made that consensus public reason's most thoroughgoing application to healthcare so far is inadequate to the task of deliberation and decision-making about the allocation of public resources in several specific aspects of healthcare and between healthcare's different decisionmaking levels. The indeterminacy of public reason, demonstrated in respect of the determination of death, has been shown to apply more broadly. While the limits of public reason's competence in healthcare has not been fully demonstrated, the description of medical professionalism's far more competent handling of complex questions of risk, value and responsibility alongside other matters about which public reason must be indeterminate has put on display a promising alternative which avoids the limitations of consensus public reason by more faithfully respecting the participatory expectations of citizens in respect of their health. Collaborative deliberation, understood on both an individual and communal level, has the capacity to incorporate comprehensive reasoning in arriving at decisions which are appropriately justified, considering the existential questions which health and its loss present.

\footnotetext{
33 There is affinity between this societal debate between comprehensive doctrines in collaborative deliberation and 'argumentative democracy'. In the latter, 'citizens openly and honestly deliberate with one another on the basis of their full belief-value sets, before voting on the basis of their best judgment of the overall balance of (moral) reasons. Such deliberation includes seeking to understand and respond to others' reasons and arguments, and trying to persuade others of the merits of one's position, while being open to persuasion.' (Billingham and Chaplin 2019: 143).
} 


\section{Acknowledgements}

I am very grateful to the editors of this journal issue, Paul Billingham and Jonathan Chaplin for their unstinting and generous guidance and advice with respect to the argument of this article. I am also grateful for two anonymous reviewers whose detailed and perceptive criticisms enabled me to improve the argument. Any defects, of course, remain my own.

Author information

Joshua Hordern, Associate Professor of Christian Ethics, Faculty of Theology and Religion, Harris Manchester College, University of Oxford, joshua.hordern@,theology.ox.ac.uk, www.healthcarevalues.ox.ac.uk @oxfordhvp.

\section{References}

Billingham, P. 'Convergence Justifications Within Political Liberalism: A Defence', Res Publica 22.2 (2016):135-53

Billingham, P. and Chaplin, J. 'Law, religion and public reason', in Handbook of the Interdisciplinary Study of Law and Religion, Doe, N. et al. (eds.) (Edward Elgar, 2019):128-148

Daniels, N. 'Rights to health care and distributive justice: Programmatic worries' Journal of Medicine and Philosophy 4.2(1979):174-191

Daniels, N. Just Health Care (CUP 1985)

Daniels, N. Just health: meeting health needs fairly (CUP, 2008)

Darr, A. HGSG Briefing Paper: Consanguineous Marriage and Inherited Disorders (2010)

Darr A. et al. 'Addressing key issues in the consanguinity-related risk of autosomal recessive disorders in consanguineous communities: lessons from a qualitative study of British Pakistanis', Journal of Community Genetics 7 (2016):65-79

Downs, J.A. et al. 'Educating Religious Leaders to Promote Uptake of Male Circumcision in 'Tanzania: A Cluster Randomised Trial.' The Lancet 389.10074 (2017):1124-132

Elwyn, G et al. 'Collaborative Deliberation: A Model for Patient Care', Patient Education and Counselling, 97(2014):158-64

Friedman, A. 'Beyond Accountability For Reasonableness'. Bioethics 22(2008):101-112

Galarneau, C. Communities of Health Care Justice (Rutgers University Press, 2016)

Gaus, G. Justificatory Liberalism (OUP, 1996)

General Medical Council, Personal beliefs and medical practice (GMC, 2013)

Gulbrandsen, P. et al. 'Shared Decision-Making as an Existential Journey: Aiming for Restored Autonomous Capacity', Patient Education and Counseling 99(2016):1505-10

Heginbotham, C. Values-based Commissioning of Health and Social Care (CUP, 2012) 
Herring J. et al. 'Elbow room for best practice? Montgomery, patients' values, and balanced decision-making in person-centred care', Medical Law Review 25(2017):582-603

Hordern J. 'Self-Knowledge and Risk in Stratified Medicine', The New Bioethics 23:1(2017):55-63

Hordern, J. 'Religion, culture and conscience', Medicine 44:10(2020a):640-643

Hordern, J. Compassion in Healthcare: Pilgrimage, Practice and Civic Life (OUP, 2020b)

Khan, N. et al. 'Developing and Evaluating a Culturally Appropriate Genetic Service for Consanguineous South Asian Families' Journal of Community Genetics 1.2(2010):73-81

Laborde, C. Liberalism's Religion (Harvard University Press, 2017)

Laborde, C. 'Abortion, Marriage and Cognate Problems', The American Journal of Jurisprudence 63:1(2018):33-48

March, A. 'Rethinking the Public Use of Religious Reasons', in Bailey, T and Gentile, V. (eds.), Rawls and Religion, Columbia University Press, 2015, 97-130

Miller, F.G. and Truog, R. Death, Dying, and Organ Transplantation: Reconstructing Medical Ethics at the End of Life (OUP, 2011)

Mkhonto F. and Hanssen I. 'When people with dementia are perceived as witches. Consequences for patients and nurse education in South Africa.' Journal of Clinical Nursing 27(2018):e169-e176

NICE, Social Value Judgments (2008)

Nussbaum, M. 'Women and Equality: The Capabilities Approach', International Labour Review 138.3(1999):227-45

Nussbaum, M. Upheavals of Thought: The Intelligence of Emotions (CUP, 2001)

Quong, J. Liberalism Without Perfection (OUP, 2011)

Rawls, J., 'The idea of public reason revisited', The University of Chicago Law Review. 64(1997):765807

Rawls, J. Political Liberalism (Columbia University Press, 2005)

Rid A. 'Justice and procedure: how does "accountability for reasonableness" result in fair limitsetting decisions?' Journal of Medical Ethics 35(2009):12-16

Rumbold, B et al. 'Public Reasoning and Health-Care Priority Setting: The Case of NICE', Kennedy Institute of Ethics Journal 27:1(2017):107-134

Salway, S. et al. 'How Should Health Policy and Practice Respond to the Increased Genetic Risk Associated with Close Relative Marriage? Results of a UK Delphi Consensus Building Exercise', BMJ Open 9.7(2019):E028928 
Schwartzman, M. 'The Completeness of Public Reason', Politics, Pbilosophy, \& Economics, 2004:3: $191-220$

Tweedie, J. Hordern, J. and Dacre J. Advancing Medical Professionalism (RCP, 2018)

Waldron, J. One Another's Equals: The Basis of Human Equality (Harvard University Press, 2017)

Watkins, Y. J. et al. 'Spiritual and Religious Beliefs and Practices and Social Support's Relationship to Diabetes Self-Care Activities in African Americans', The Diabetes Educator, 39:2(2013):231-239

Williams J. 'Public Reason and Prenatal Moral Status', Journal of Ethics 19(2015):23-52

Williams, J. 'Death and Consensus Liberalism', Philosophers' Imprint 17.20(2017):1-30 